\title{
Effect of Volume History on Measurements of Respiratory Mechanics Using the Interrupter Technique
}

\author{
N. J. FREEZER, T. NICOLAI, AND P. D. SLY \\ Faculty of Medicine, University of Southampton, England [N.J.F.]; Universitats-Kinderklinik, Münich, Germany \\ [T.N.J; and Division of Clinical Sciences, Western Australian Research Institute for Child Health. The Children's \\ Hospital Medical Centre, Perth, Western Australia [P.D.S.]
}

\begin{abstract}
The importance of the viscoelastic properties of the tissues of the respiratory system has recently been recognized, and lung models have been produced to describe the resistive and viscoelastic properties of the lung. The pulmonary mechanics of 10 rabbits were studied using the interrupter technique to assess the effect of volume history on the resistive and viscoelastic elements of the respiratory system. The influence of the tone of the muscles of respiration was also studied. In healthy lungs, the resistive and viscoelastic elements of the lung are dependent on the volume history of the respiratory system and are significantly lower if these elements do not reach a resting position before expiration. The chest wall made a significant contribution to the resistive and viscoelastic elements of the respiratory system, which was also dependent on the lung volume history. The tone of the muscles of respiration had no effect on the resistive or viscoelastic elements of the respiratory system. (Pediatr Res 33: 261-266, 1993)
\end{abstract}

\section{Abbreviations}

$R_{1}$, resistance of respiratory system

$R_{2}$, dissipative properties of lung or chest wall

$E_{1}$, static elastance of respiratory system

$\mathbf{E}_{2}$, elastic properties

ET, endotracheal

FRC, functional residual capacity

Pao, airway opening pressure

Pes, esophageal pressure

Pdiff, static recoil pressure of respiratory system

Pinit, resistance pressure drop across airways and chest wall

Rinit, Newtonian flow resistance of airways and chest wall

Rrs, flow resistance of the respiratory system

ANOVA, analysis of variance

$\mathbf{R}_{\mathrm{ETT}}$, endotracheal tube resistance

Recently, the importance of the viscoelastic properties of the tissues of the respiratory system has been recognized $(1-10)$. The two-compartment model for the lung that best represents experimental data consists of a single alveolar compartment surrounded by a viscoelastic tissue compartment (11), and models have been produced to describe the resistive and viscoelastic properties of the lung. This model can be represented by springs

Received August 19, 1992; accepted October 15, 1992.

Correspondence: Dr. N. Freezer, Medicine 1, Southampton General Hospital, Southampton, England SO9 4XY.

Supported in part by a grant from the Royal Children's Hospital Research Foundation, Melbourne. N.J.F. was a Fellow of the Foundation.

Work performed at the Royal Children's Hospital, Parkville, Victoria, Australia. and dashpots as shown in Figure 1, where $R_{1}$ represents the airway resistance and any Newtonian component of tissue resistance that is in parallel with another three elements $\left(\mathrm{E}_{1}, \mathrm{E}_{2}\right.$, and $R_{2}$ ) in the form of the Kelvin body, an elastic element in parallel with a series elastance-resistance. $E_{1}$ represents the static elastance of the respiratory system and $E_{2}$ and $R_{2}$ the dissipative and elastic properties of the tissues of the lung and chest wall (12). If the two bars at either end of the model are moved relative to each other to represent the changes in volume during respiration, the properties of $R_{1}, E_{1}, R_{2}$, and $E_{2}$ determine the behavior of the model. If the bars are stopped abruptly, simulating a flow interruption, the "energy dissipation" in $R_{1}$ and $E_{1}$ will stop immediately; however, some time will be required for $R_{2}$ and $E_{2}$ to reach their resting position. This model allows a better description of the changes in Pao observed after rapid airway occlusions during passive expiration than the traditional one-compartment model of the respiratory system (13).

If we accept that Pes represents the contribution of the chest wall, and that the chest wall exhibits viscoelastic behavior, a similar model may be used to describe the changes observed in Pes after flow interruption during passive expiration. Separate spring and dashpot models may therefore be used to represent the lung and the chest wall, with each model having different values of elastance and resistance.

Recently, the interrupter technique, adapted from that introduced by von Neergaard and Wirz in 1927 (14), has been used to measure the respiratory mechanics of intubated, mechanically ventilated animals and humans $(1,11,15,16)$. This technique allows a more detailed examination of the respiratory system after an abrupt flow interruption in that it allows the respiratory system to be considered as a two-compartment model, with the Newtonian "flow resistance" of the airways and chest wall considered separately from the peripheral phenomenon of stress adaptation and gas redistribution (pendelluft).

Flow interruptions are frequently performed during expiration because of the better signal-to-noise ratio. Under these circumstances, an end-inspiratory occlusion is usually performed before a second airway occlusion during passive expiration. During the end-inspiratory airway occlusion, all the elements of the respiratory system reach a resting position, and the effect of the preceding inspiratory breath is dissipated before passive expiration (13). If the end-inspiratory airway occlusion is omitted, the volume history of the respiratory system is changed and the resistive and viscoelastic elements of the respiratory system may not reach a resting position before the onset of passive expiration. This may significantly change the properties of the resistive and viscoelastic elements of the lung and chest wall.

Animals are frequently paralyzed when studied. In clinical studies performed in mechanically ventilated infants and young children, muscle relaxation may not be possible (17). Tone in the muscles of the chest wall may also contribute to stress 


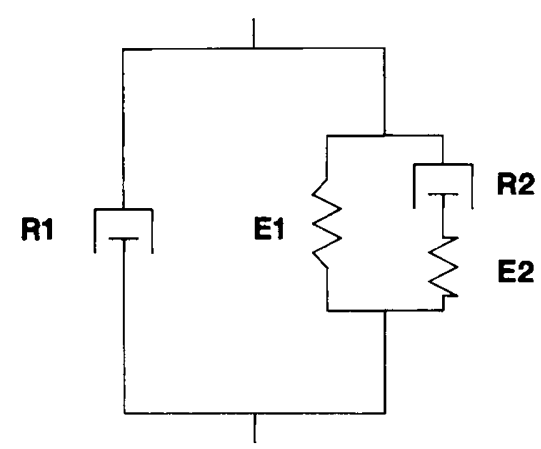

Fig. 1. The spring and dashpot model. $R_{1}$ represents the resistance and $E_{1}$ the static elastance of the respiratory system. $R_{2}$ and $E_{2}$ represent the dissipative and elastic properties of the lung or chest wall. $E_{1}, R_{2}$, and $E_{2}$ are the Kelvin body. Distance between the horizontal bars is the analog of lung volume, and tension between these bars is the analog of Pao.

adaptation; therefore, respiratory mechanics were measured before and after paralysis of the muscles of respiration.

This study was undertaken to examine the effect of changing the volume history of the respiratory system on the resistive and viscoelastic elements of the lung and chest wall and to assess the contribution of the tone of the muscles of respiration. Rabbits were chosen because they have a very compliant chest wall similar to that of infants. The chest wall of cats and dogs has been shown to contribute significantly to the resistance of the respiratory system $(5,12)$.

\section{MATERIALS AND METHODS}

Ten rabbits $(1.0-1.7 \mathrm{~kg})$ were anesthetized intramuscularly with ketamine $(40 \mathrm{mg} / \mathrm{kg})$ and xylazine $(8 \mathrm{mg} / \mathrm{kg})$ and then intubated with a $3.0-\mathrm{mm}$ (internal diameter) Portex ET tube (Portex Limited, Kent, England). The rabbits were mechanically ventilated in the supine position with a fraction of inspired $\mathrm{O}_{2}$ of 0.21 , using a time-cycled ventilator (Vickers Infant Ventilator) at $0.33 \mathrm{~Hz}$, a peak inspiratory pressure of 15 to $20 \mathrm{~cm} \mathrm{H}_{2} \mathrm{O}$ and a positive end-expiratory pressure of 3 to $5 \mathrm{~cm} \mathrm{H}_{2} \mathrm{O}$. Although the chest wall was intact, positive end-expiratory pressure was used to simulate the mechanical ventilation of infants. The ventilation was adjusted so that the end tidal $\mathrm{CO}_{2}$ was 3 to $5 \%$. The ET tube was not cuffed; however, any leak around the ET tube was easily controlled with gentle external cricoid pressure.

A heated screen pneumotachograph with a dead space of 1.80 $\mathrm{mL}$ was used to measure flow (model 8300A, Hans Rudolph, Inc., Kansas City, MO). Flow through the pneumotachograph was laminar from 0 to $10 \mathrm{~L} / \mathrm{min}$, and the signal pressure was linear from 0 to $10 \mathrm{~L} / \mathrm{min}$ with a back pressure of 0.1 to $0.9 \mathrm{~cm}$ $\mathrm{H}_{2} \mathrm{O}$, depending on the gas flow. The occlusion valve had a dead space of $2.0 \mathrm{~mL}$, was pressure-tight to 75 pounds per square inch $\left(5280 \mathrm{~cm} \mathrm{H}_{2} \mathrm{O}\right)$, and closed in $12 \mathrm{~ms}$. Approval was obtained from the Animal Experimentation Ethics Committee of the Royal Children's Hospital Research Foundation.

Signal Processing. Pao and Pes were measured with differential pressure transducers (CTQH 360, Applied Measurement, Australia). Flow was measured at the airway opening with a differential pressure transducer (Statham, model no. 10253). During the measurements, the rabbits were mechanically ventilated. All signals were passed through a three-channel signal conditioner (043A, Applied Measurement) to filter and amplify the signals before digitization. Low-pass antialiasing filters were used with the cutoff frequency set at $100 \mathrm{~Hz}$. The signals were recorded by a 12-bit analog-digital converter (DT 2801-A, Data Translation, Marlborough, MA) at a frequency of $250 \mathrm{~Hz}$ and stored on a personal computer. The flow signal was numerically integrated to give volume. Data analysis was performed using Anadat and Labdat 3.1 software (Labdat, RHT-Infodat, Montreal, Canada).
Within each protocol, the lung volumes at which Rrs and Pdiff were calculated were sequenced in a random manner; however, the measurements of respiratory mechanics were recorded in the anesthetized, nonparalyzed state before muscle paralysis was induced. In each rabbit, the ventilator settings were kept constant throughout the experiment.

Interrupter Technique. If the flow of gas at the airway opening is suddenly interrupted during passive expiration by a rapidly shutting valve, one observes two distinct pressure changes just proximal to the valve. The first change, Pinit, is virtually immediate and reflects the resistive pressure drop across the airways $(13,18)$ and the chest wall $(19)$. This is followed by a second, slower pressure change, Pdiff, to a plateau equal to the static recoil pressure of the respiratory system (Fig. 2). During flow interruption, the reduction in pressure due to volume loss from continuing gas exchange should be negligible (20). It is assumed that the moving elements of the respiratory system have no mass and that the column of gas is incompressible. Suddenly bringing a column of air to rest results in a transfer of kinetic energy to potential energy, which is manifest as an increase in pressure; however, this has been shown to be negligible in the lung (21).

As the flow was not interrupted instantaneously, Pinit and Pdiff were obtained using the method of Sly and Bates (22), with curves being fitted to the preinterruption pressure $(\mathrm{Pao})$ and flow signals from 20 to $200 \mathrm{~ms}$ before the time of midpoint valve closure. Curves were also fitted to the postinterruption pressure (Pao) and flow data for 20 to $1000 \mathrm{~ms}$ after the time of midpoint valve closure. The fitted curves were then extrapolated over the final $20 \mathrm{~ms}$ to the midpoint time. Dividing Pinit by the flow just before interruption gives the initial resistance, Rinit, which represents the Newtonian flow resistance of the airways and chest wall $(11,17)$. Pdiff reflects stress adaptation within the tissues of the lung and chest wall, a manifestation of their viscoelastic properties, together with any redistribution of gases (pendelluft) occurring between lung units at different pressures at the time of flow interruption $(13,18)$.

Calculation of $R_{E T T T}$. The resistance added to the respiratory system resistance by the ET tube, $\mathrm{R}_{\mathrm{ETT}}$, and the measuring equipment must be estimated in any measurement of respiratory mechanics (1). $R_{\mathrm{ErT}}$ is flow-dependent and related to the internal diameter and length of the tube $(1,23)$. The static flow-pressure curves for ET tubes have been shown to be nonlinear (24) and the resistance $(R)$ of the tube may be estimated by fitting a second-order polynomial to the pressure-flow relationship using the equation

$$
\mathrm{P}=\mathrm{K}_{1} \dot{\mathrm{V}}+\mathrm{K}_{2} \dot{\mathrm{V}}^{2}
$$

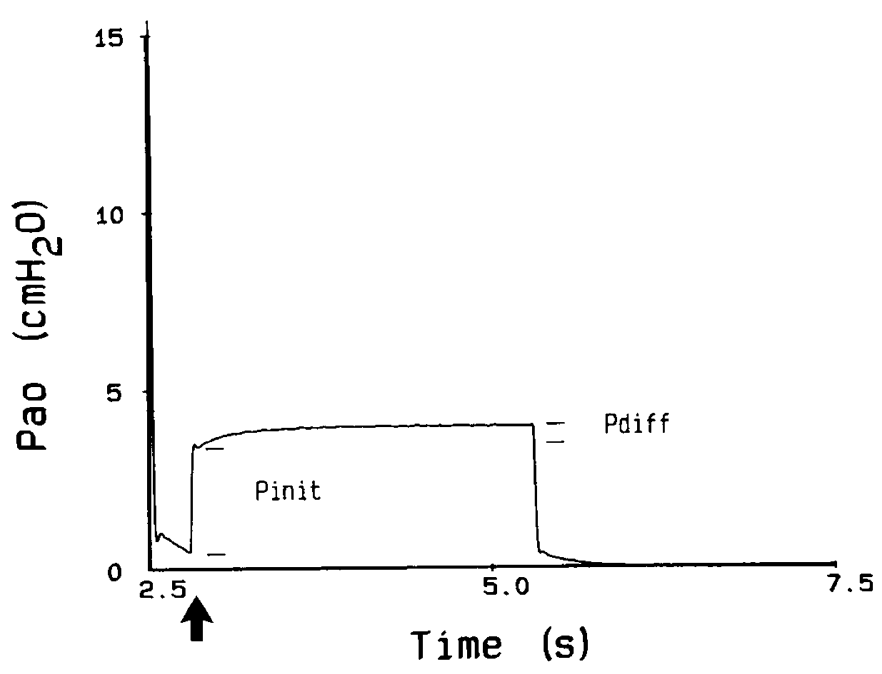

Fig. 2. Pao vs time. The changes in Pao observed after flow interruption (arrow) during passive expiration are illustrated. 
or

$$
\mathrm{R}=\mathrm{K}_{1}+\mathrm{K}_{2} \dot{\mathrm{V}}
$$

where $P$ is the pressure across the tube, $K_{1}$ and $K_{2}$ are the Rohrer constants, and $\dot{V}$ is the flow of gas through the tube. $K_{1}$ and $K_{2}$ vary with the dimensions of the tube. When $R$ is measured in both inspiration and expiration, the expiratory resistance is $\leq 10 \%$ higher presumably because of a difference in the flow profiles that occur in each direction (25).

The resistance of the ET tube may then be subtracted from Rinit to give the Newtonian Rrs, using the equation

$$
\text { Rrs }=\text { Rinit }-\left[K_{1}+\left(K_{2} \times \dot{V}\right)\right]
$$

The flow-dependent resistance of the ET tubes used was measured for inspiratory and expiratory flows at various tube lengths. The ET tubes were placed in their usual position in the occlusion valve and pneumotachograph assembly used throughout the study. A vacuum cleaner was attached to the equipment to generate the flow in both directions. The flows used were those encountered in the measurement of the pulmonary mechanics of the rabbits and were within the linearity of the pneumotachograph $(0$ to $10 \mathrm{~L} / \mathrm{min})$. A variable resistor was used to control the voltage to the vacuum cleaner and thus the flow through the tubes. Three values of $\mathrm{K}_{1}$ and $\mathrm{K}_{2}$ were calculated for the ET tubes at a given length by fitting a second-order polynomial through the data points. Only results with a coefficient of determination $\geq 0.9990$ were accepted. The mean of these values was used to create a regression equation for values of $\mathrm{K}_{1}$ and $\mathrm{K}_{2}$, and from this equation the values of $K_{1}$ and $K_{2}$ were obtained for the ET tubes at various lengths (Table 1).

Contribution of Chest Wall. Pes was measured to partition the respiratory mechanics into compartments representing the lung and chest wall. The contribution of the lung may be assessed by using transpulmonary pressure (Ptp), which may be calculated from the equation

$$
\text { Ptp }=\text { Pao }- \text { Pes }
$$

A thin-walled latex esophageal balloon was inserted and filled with $0.5 \mathrm{~mL}$ of air. It was positioned so that the pressure change at the airway opening ( $\triangle \mathrm{PaO}$ ) was equal to the change in Pes ( $\triangle$ Pes) during spontaneous occluded breathing efforts. The same balloon was used for all rabbits.

Study Protocol. Airway occlusions were performed no more frequently than every fifth breath to allow adequate ventilation between measurements. The lung volume at which Rrs and Pdiff were calculated was expressed as a percentage of the volume exhaled during passive expiration to functional residual capacity (percentage of volume above FRC).

Expiratory occlusion with preceding end-inspiratory occlusion. After a period of mechanical ventilation, the valve was closed for $2.5 \mathrm{~s}$ at end-expiration to provide a constant-volume history and allow the effect of inspiration to be dissipated before expi-

Table 1. Rohrer constants

\begin{tabular}{cccccc}
\hline \multirow{2}{*}{$\begin{array}{c}\text { ET tube } \\
\text { Iength }(\mathrm{cm})^{*}\end{array}$} & \multicolumn{2}{c}{ Expiration } & & \multicolumn{2}{c}{ Inspiration } \\
\cline { 2 - 3 } \cline { 5 - 6 } & $\mathrm{K}_{1}$ & $\mathrm{~K}_{2}$ & & $\mathrm{~K}_{1}$ & $\mathrm{~K}_{2}$ \\
\hline 17.5 & 0.028921 & 0.000162 & & 0.021522 & 0.000180 \\
16.5 & 0.027974 & 0.000156 & & 0.019851 & 0.000179 \\
15.5 & 0.027027 & 0.000150 & & 0.018180 & 0.000178 \\
14.5 & 0.026080 & 0.000144 & & 0.016509 & 0.000177 \\
13.5 & 0.025133 & 0.000138 & & 0.014838 & 0.000176 \\
12.5 & 0.024186 & 0.000132 & & 0.013167 & 0.000175 \\
12.0 & 0.023713 & 0.000129 & 0.012332 & 0.000175 \\
11.5 & 0.023239 & 0.000126 & 0.011496 & 0.000174 \\
11.0 & 0.22766 & 0.000123 & 0.010661 & 0.000174 \\
10.5 & 0.22292 & 0.000120 & 0.009825 & 0.000173 \\
10.0 & 0.021819 & 0.000117 & 0.008990 & 0.000173 \\
\hline
\end{tabular}

*ET tube internal diameter $=3.0 \mathrm{~mm}$ for all. ration commenced. During this occlusion, the ventilator circuit was disconnected. The valve was then opened to allow passive expiration for times varying between 100 and $600 \mathrm{~ms}$ and then reclosed for $2.5 \mathrm{~s}$ to allow the calculation of Rrs and Pdiff at various lung volumes. The valve was then opened again for $5 \mathrm{~s}$ to allow the rabbit to breathe out to passive FRC before the ventilator circuit was reconnected (Fig. 3).

Expiratory occlusion without preceding end-inspiratory occlusion. After a period of mechanical ventilation, a single airway occlusion was performed during passive expiration for the calculation of Rrs and Pdiff (Fig. 4). The ventilator was disconnected during the airway occlusion; therefore, the animals exhaled through the ventilator circuit during the initial part of passive expiration. After the flow interruption, they were allowed to exhale to passive FRC before the ventilator circuit was reconnected.

Contribution of muscles of respiration. All data were collected with the rabbits anesthetized and mechanically ventilated. They did not breathe spontaneously during this period. They were removed from the ventilator and allowed to establish spontaneous respiration before paralysis was achieved with i.v. pancuronium. The dose (approximately $2 \mathrm{mg} / \mathrm{kg}$ ) was titrated until the rabbit ceased spontaneous respiration. Rrs and Pdiff were therefore calculated before and after paralysis of the muscles of respiration.

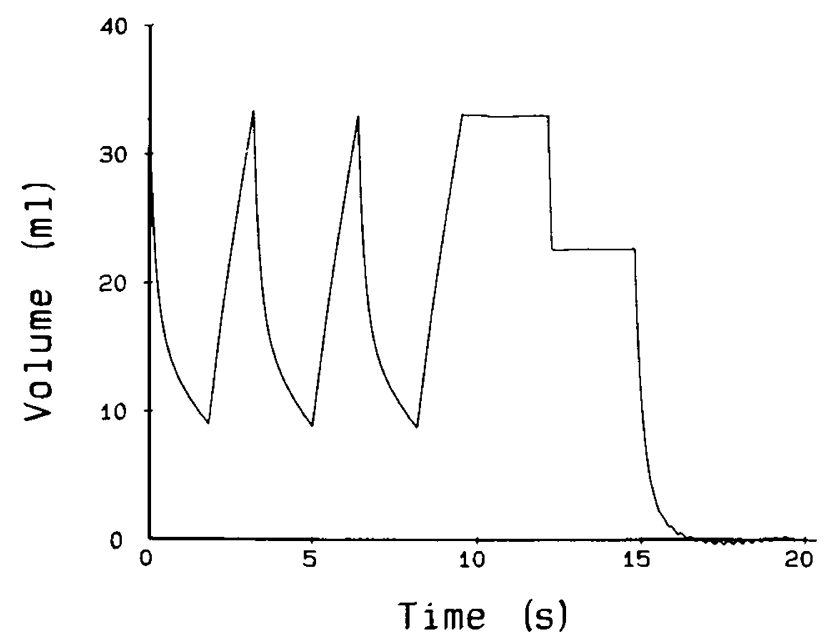

Fig. 3. Lung volume vs time. Expiratory occlusion with a preceding end-inspiratory occlusion. Zero volume is the FRC of the respiratory system.

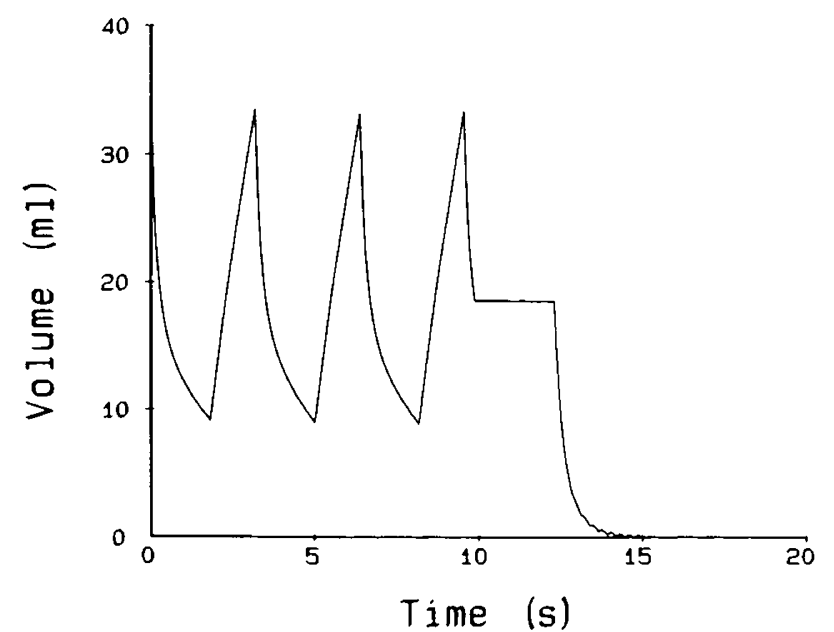

Fig. 4. Lung volume vs time. Expiratory occlusion without a preceding end-inspiratory occlusion. Zero volume is the FRC of the respiratory system. 
Statistical Analysis. The data were analyzed using Minitab 7.1 statistical software. Generalized linear modeling was used to implement an ANOVA with the data nested for lung volume. The slopes of Rrs and Pdiff versus lung volume under the different experimental conditions were then compared. In addition, repeated-measures ANOVA and linear regression were used when appropriate. The null hypothesis was rejected if $p$ was $<0.05$.

\section{RESULTS}

The rabbits were mechanically ventilated with a mean tidal volume of $28.2 \pm 4.9(\mathrm{SD}) \mathrm{mL}(18 \mathrm{~mL} / \mathrm{kg})$. The flow just before the airway occlusion was significantly lower at all lung volumes when the end-inspiratory occlusion was omitted (ANOVA, $F=$ $16.50 ; p<0.0001$ ) (Table 2). Rinit and Rrs were significantly flow-dependent $(p<0.0001)$; however, the change in flow accounted for only some of the variability of Rinit and Rrs (Rinit $=0.0532+0.0003$ flow, $r^{2}=0.20 ;$ and $\operatorname{Rrs}=0.01433+0.0001$ flow, $r^{2}=0.05$ ). There was no relationship between Rinit or Rrs and lung volume. Pdiff was not flow-dependent but increased significantly as the lung volume decreased $\left(r^{2}=0.6 ; p<0.0001\right)$. The within-subject coefficient of variation for repeated measures was approximately $10 \%$ for Rinit and $8 \%$ for Pdiff.

Expiratory occlusion with preceding end-inspiratory occlusion. The chest wall made a significant contribution to Pdiff (ANOVA, $F=5.07 ; p<0.0001$ ), and its contribution increased as the lung volume decreased (Fig. 5). The chest wall did not make a significant contribution to Rrs (ANOVA, $F=0.39 ; p=0.951$ ), inasmuch as Pinit in the Pes measurements was small.

Expiratory occlusion without preceding end-inspiratory occlusion. At the highest lung volumes, Pdiff was not influenced by the volume history of the lung, and the stress adaptation of the lung was small. Pdiff increased at lower lung volumes and was significantly lower (ANOVA, $F=23.32 ; p<0.0001$ ) when the end-inspiratory occlusion was omitted (Fig. 6). Rrs was signifi-

Table 2. Flow before airway occlusion during passive expiration

\begin{tabular}{ccc}
\hline \multirow{2}{*}{$\begin{array}{c}\text { Lung volume } \\
(\% \text { vol }>\text { FRC })\end{array}$} & \multicolumn{2}{c}{ End-inspiratory occlusion* } \\
\cline { 2 - 3 } & Performed & Omitted \\
\hline $70-79$ & $95 \pm 7.8$ & $47 \pm 3.6$ \\
$60-69$ & $76 \pm 4.7$ & $35 \pm 4.5$ \\
$50-59$ & $73 \pm 3.6$ & $33 \pm 1.1$ \\
$40-49$ & $56 \pm 2.3$ & $25 \pm 1.3$ \\
$30-39$ & $50 \pm 2.6$ & $17 \pm 1.0$ \\
$20-29$ & $36 \pm 1.3$ & $9 \pm 0.8$ \\
\hline
\end{tabular}

* Values are group mean $\pm \mathrm{SEM}$ in $\mathrm{mL} / \mathrm{s}$.

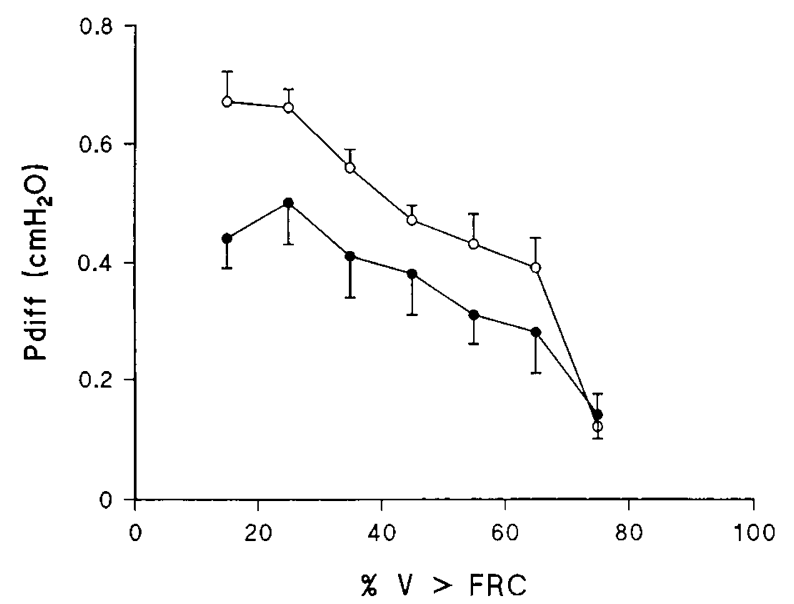

Fig. 5. Pdiff vs lung volume. End-inspiratory occlusion performed. Open circles, Pao (lung and chest wall). Solid circles, transpulmonary pressure (lung only). Values are group mean \pm SEM.

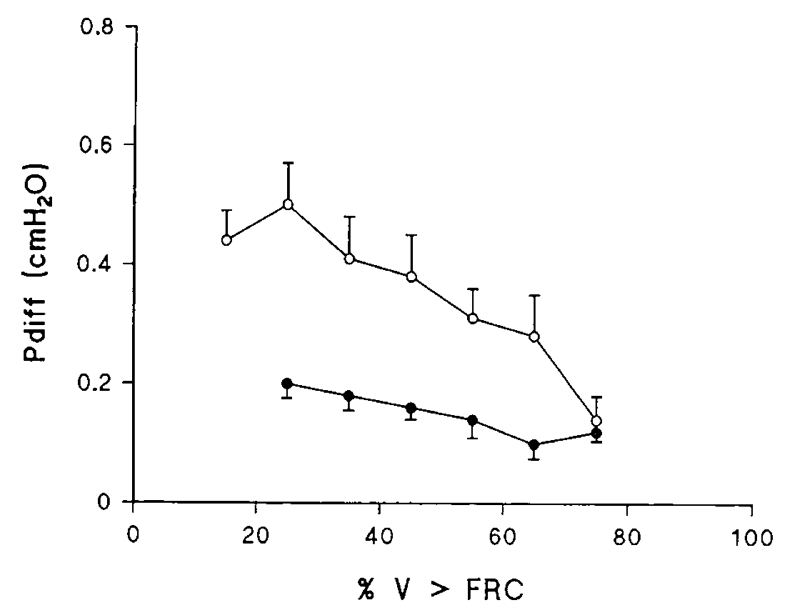

Fig. 6. Lung Pdiff vs lung volume. Open circles, end-inspiratory occlusion performed. Solid circles, end-inspiratory occlusion omitted Values are group mean \pm SEM.

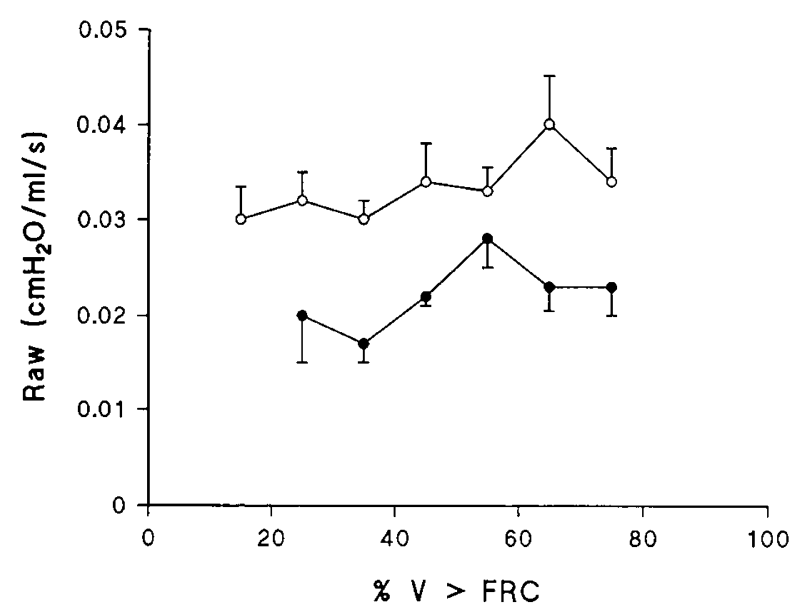

Fig. 7. Lung Rrs vs lung volume. Open circles, end-inspiratory occlusion performed. Solid circles, end-inspiratory occlusion omitted. Values are group mean \pm SEM.

cantly lower (ANOVA, $F=16.34 ; p<0.0001$ ) when the endinspiratory occlusion was omitted at all of the lung volumes studied (Fig. 7).

The chest wall made a significant contribution to Pdiff (ANOVA, $F=11.32 ; p<0.0001$ ). The contribution increased as the lung volume decreased to $50 \%$ above FRC and then decreased at lower lung volumes (Fig. 8). The chest wall also contributed significantly to $\operatorname{Rrs}$ (ANOVA, $F=2.03 ; p<0.05$ ), particularly at the lower lung volumes (Fig. 9).

Paralysis of muscles of respiration. Regardless of the volume history of the lung, removal of the tone of the muscles of respiration, including the diaphragm and chest wall, by paralysis with pancuronium did not significantly alter the values of Rrs or Pdiff or alter their relationship with lung volume.

\section{DISCUSSION}

The resistance of the airways is directly related to the flow through the airways and inversely related to the airway diameter. When the end-inspiratory occlusion was omitted, the significantly lower flow before flow interruption may, at least in part, be explained by the method of data collection. When an endinspiratory occlusion was performed, passive expiration was against atmospheric pressure. When the end-inspiratory occlusion was omitted, passive expiration before the expiratory flow interruption was against the resistance of the expiratory limb of the ventilator circuit. The results of this study support the flow 


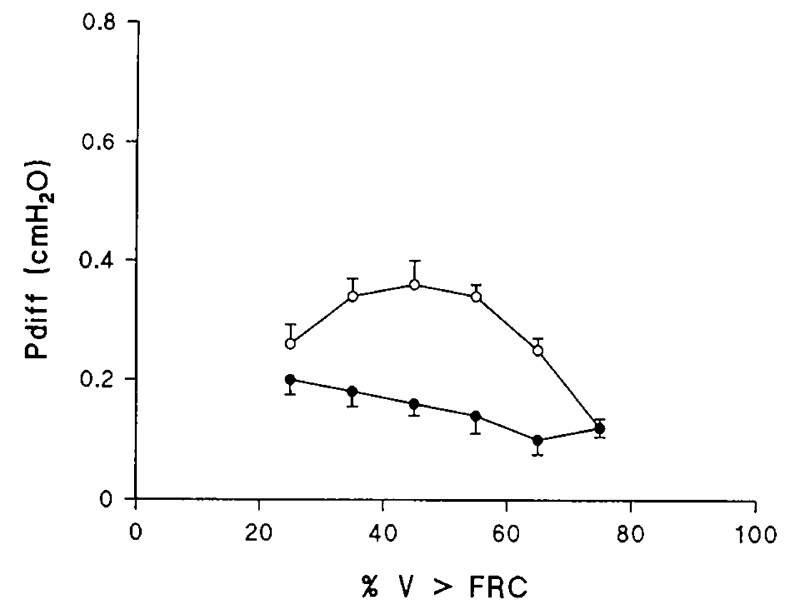

Fig. 8. Pdiff $v s$ lung volume. End-inspiratory occlusion omitted. Open circles, Pao (lung and chest wall). Solid circles, transpulmonary pressure (lung only). Values are group mean \pm SEM.

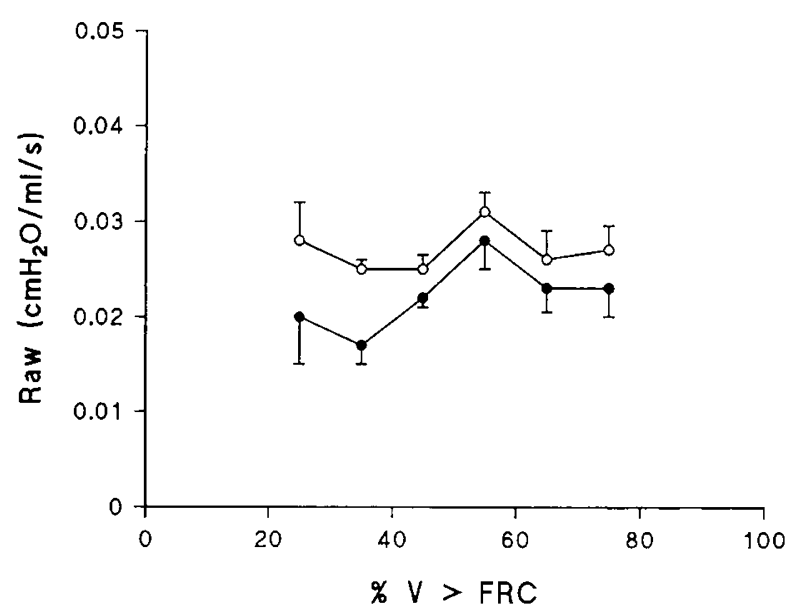

Fig. 9. Rrs vs lung volume. End-inspiratory occlusion omitted. Open circles, Pao (lung and chest wall). Solid circles, transpulmonary pressure (lung only). Values are group mean \pm SEM.

dependence of $\mathrm{R}_{\mathrm{ETT}}$ and Rrs but suggest that other factors may make an important contribution to the flow resistance of the airways and chest wall.

Mead et al. (26) used a condom model to represent the air spaces and study the distribution of stress in the lungs. They demonstrated that the interdependence of air space distension bears on a number of aspects of pulmonary function, including the static and dynamic stability of the air spaces and the forces distending the airways and blood vessels within the lung. When the interrupter technique is used to study the mechanics of the respiratory system, the volume history of the lung may be important in determining the stresses distending the intrapulmonary air spaces. If an end-inspiratory occlusion is performed, the stresses distending the intrapulmonary airways will reach a resting position before passive expiration. This may decrease the diameter of the intrapulmonary airways and contribute to the higher Rrs observed during passive expiration under these experimental conditions.

Bates et al. (11) have demonstrated in dogs without an intact chest wall that Rrs represents the flow resistance of the airways. In this study, the chest wall made a significant contribution to Rrs when the end-inspiratory occlusion was omitted. This suggests that Rrs includes a Newtonian component in the chest wall that is either dissipated by performing an end-inspiratory occlusion or is only apparent when passive expiration is "braked," e.g. by expiration against the expiratory limb of the ventilator circuit.

We did not observe the expected decrease in Rrs at higher lung volumes. The $\mathrm{R}_{\text {ETT }}$ may have masked any change in Rrs with a change in lung volume, inasmuch as ET tubes do not change in diameter during respiration, and errors are undoubtedly present in the calculation of $\mathrm{R}_{\mathrm{ETT}}$. Loring et al. (27) demonstrated that the $R_{E T r}$ is influenced by the kinetic energy losses due to flow separation, which is dependent on the geometry at the junction of the ET tube and the trachea in vivo and the geometry at the end of the ET tube in isolation. Any errors in the calculation of $\mathrm{R}_{\mathrm{ETT}}$ arise from kinetic energy dissipation at the end of the ET tube and are dependent on the magnitude of the kinetic term $1 / 2$ $\mathrm{p}(\dot{\mathrm{V}} / \mathrm{A})^{2}$, where $\mathrm{p}$ is the gas density, $\dot{\mathrm{V}}$ is the gas flow, and $\mathrm{A}$ is the area at a given cross section. Kinetic energy dissipation will be greater at high flow rates with dense gases and narrow ET tubes. The ET tubes used in this study had an internal diameter of $3.0 \mathrm{~mm}$, and therefore the $\mathrm{R}_{\mathrm{Err}}$ calculated in vitro may significantly overestimate the in vivo $\mathrm{R}_{\mathrm{ETT}}$.

The in vitro $\mathrm{R}_{\mathrm{ETT}}$ may have more accurately estimated the in vivo $\mathrm{R}_{\mathrm{ETT}}$ if the distal tip had been inserted into another tube with an internal diameter equal to the internal diameter of the trachea of the rabbits studied, as this would have reduced the cross-sectional area at the distal end of the ET tube and therefore flow separation and kinetic energy loss (27). However, flow separation in vivo depends on many factors, including the geometry of the ET tube-tracheal connection, the exact area of the trachea, the distance the ET tube is inserted into the trachea and the position or angulation of the distal ET tube. In addition, $\mathrm{R}_{\mathrm{ETT}}$ may be affected by the presence of secretions in the ET tube, and the diameter of the trachea may not be equal in inspiration and expiration. These factors make it difficult if not impossible to accurately calculate the in vivo $\mathrm{R}_{\mathrm{ETT}}$.

In healthy lungs, Pdiff reflects the viscoelastic properties of the respiratory system, inasmuch as pendelluft has been shown to be minimal $(11,18)$. Although the present study was performed in close-chested animals, there is no reason to suspect that the presence of an intact chest wall should make ventilation distribution less homogeneous and promote pendelluft. However, it is not possible to exclude the presence of pendelluft in our current experimental model; thus, our remarks about stress adaptation must be interpreted as including a possible, albeit unlikely, contribution from gas redistribution after flow interruption.

Sly et al. $(28,29)$ have recently described stress adaptation after midexpiratory flow interruption using a viscoelastic time constant. In the Kelvin body model, this time constant could be calculated as

$$
T=\mathrm{R}_{2} / \mathrm{E}_{2}
$$

They demonstrated that $T$ remained remarkably constant during inhalational challenges with histamine, hypertonic saline, and methacholine if the volume history of the lung was kept constant (28). However, if flow interruptions were made at different points throughout a passive expiration, $T$ increased as expiration proceeded (29). This volume dependence is a clear example of nonlinear viscoelastic behavior that the Kelvin body cannot describe. In the present study, omitting the end-inspiratory occlusion has two potentially important effects on the volume history. An end-inspiratory occlusion allows the respiratory system to come to "rest" before the onset of expiration. For the Kelvin body model, this implies that $E_{2}$ and $R_{2}$ have reached an equilibrium position before the onset of expiration. Because the motion of these elements is likely to lag behind that in $E_{1}$ and $\mathrm{R}_{1}$, omitting an end-inspiratory occlusion means that, in early expiration, $\mathrm{E}_{2}$ and $\mathrm{R}_{2}$ are likely still to be "moving" in an inspiratory direction. Indeed, experience tells us that occlusions made in very early expiration exhibit stress adaptation similar to occlusions made during inspiration (data not shown). Further into expiration, the degree of stress adaptation after flow interruption would be expected to be less than that seen if an endinspiratory occlusion had been made, precisely the finding of the present study.

At the time of an end-inspiratory occlusion, the animal is 
routinely disconnected from the ventilator. The subsequent expiration is made free of the retarding effect of the resistance of the expiratory limb of the ventilator circuit. Thus, a given lung volume will be reached more quickly than if the expiration occurred against the resistance of the ventilator circuit. If the viscoelastic behavior of the respiratory system is nonlinear, this time difference may be important in determining the extent of the stress adaptation seen. The single Kelvin body model is a gross oversimplification, and it would undoubtedly be more correct to include many Kelvin bodies with a distribution of time constants. With longer expiratory times, the units with shorter time constants may reach their resting position during the expiration and not contribute to stress adaptation after a flow interruption. These two phenomena may contribute to the lower values of Pdiff seen when an end-inspiratory occlusion was not performed before an expiratory flow interruption.

As is commonly observed, the ventilated rabbits studied here did not make spontaneous breathing efforts before muscle relaxation. The muscles of the chest wall would, however, have continued to have tone. Removal of the tone of the muscles of respiration by paralysis with pancuronium did not alter the values of Rrs or Pdiff or alter their relationship with the lung volume above FRC. Thus, at all of the lung volumes studied, the tone of the muscles of respiration did not contribute significantly to the elastic or resistive elements of the lung or chest wall.

The results of this study therefore suggest that the resistive and viscoelastic elements of the lung and chest wall of healthy, anesthetized, mechanically ventilated rabbits under the experimental conditions evaluated are dependent on the volume history of the respiratory system.

Acknowledgments. The authors thank Magdi Souriel, Director of the Animal Laboratory, for technical assistance; and E. Byrt, Clinical Epidemiology and Biostatistics Unit, Department of Pediatrics, University of Melbourne, for statistical advice.

\section{REFERENCES}

1. Sly PD, Brown KA, Bates JHT, Spier S, Milic-Emili J 1988 Noninvasive determination of respiratory mechanics during mechanical ventilation of neonates: a review of current and future techniques. Pediatr Pulmonol 4:3947

2. D'Angelo E, Robatto FM, Calderini E, Tavola M, Bono D, Torri G, MilicEmili J 1991 Pulmonary and chest wall mechanics in anesthetized paralyzed humans. J Appl Physiol 70:2602-2610

3. D'Angelo E, Calderini E, Torri G, Robatto FM, Bono D, Milic-Emili J 1989 Respiratory mechanics in anesthetized paralyzed humans: effects of flow, volume, and time. J Appl Physiol 67:2556-2564

4. Sato J, Davey BLK, Shardonofsky F, Bates JHT 1991 Low-frequency respiratory system resistance in the normal dog during mechanical ventilation. J Appl Physiol 70:1536-1543

5. Sly PD, Bates JHT, Kochi T, Okubo S, Milic-Emili J 1987 Frequency- dependent effects of hypercapnia on respiratory mechanics of cats. $\mathbf{J}$ Appl Physiol 62:444-450

6. Bates JHT, Decramer M, Zin WA, Harf A, Milic-Emili J, Chang HK 1986 Respiratory resistance with histamine challenge by single-breath and forced oscillation methods. J Appl Physiol 61:873-880

7. Lutchen KR, Jackson AC 1990 Effects of tidal volume and methacholine on low-frequency total respiratory impedence in dogs. J Appl Physiol 68:21282138

8. Eissa NT, Ranieri VM, Corbeil C, Chasse M, Robatto FM, Braidy J, MilicEmili $J 1991$ Analysis of behavior of the respiratory system in ARDS patients: effects of flow, volume, and time. J Appl Physiol 70:2719-2729

9. Lutchen KR, Giurdanella CA, Jackson AC 1990 Inability to separate airway from tissue properties by use of human respiratory input impedance. J Appl Physiol 68:2403-2412

10. Lutchen KR, Habib RH, Dorkin HL, Wall MA 1990 Respiratory impedance and multibreath $\mathrm{N}_{2}$ washout in healthy, asthmatic, and cystic fibrosis subjects. J Appl Physiol 68:2139-2149

11. Bates JHT, Ludwig MS, Sly PD, Brown K, Martin JG, Fredberg JJ 1988 Interrupter resistance elucidated by alveolar pressure measurement in openchested normal dogs. J Appl Physiol 65:408-414

12. Bates JHT, Brown KA, Kochi T 1989 Respiratory mechanics in the normal dog determined by expiratory flow interruption. J Appl Physiol 67:22762285

13. Bates JHT, Baconnier P, Milic-Emili J 1988 A theoretical analysis of the interrupter technique for measuring respiratory mechanics. J Appl Physiol 64:2204-2214

14. Von Neergaard J, Wirz K 1927 Die Messung der Stromungswiderstande in den Atemwegen des Menschen, insbesondere bei Asthma und Emphysem. Z Klin Med 105:51-82

15. Gottfried SB, Higgs BD, Rossi A, Carli F, Mengot PM, Calverly PMA, Zocchi L 1985 Interrupter technique for measurement of respiratory mechanics in anesthetized humans. J Appl Physiol 59:647-652

16. Sly PD, Lanteri CJ 1990 Differential responses of the airway and pulmonary tissues to inhaled histamine in young dogs. J Appl Physiol 68:1562-1567

17. Freezer NJ, Sly PD 1991 The prediction of BPD in VLBW infants. Am Rev Respir Dis 143:A724(abstr)

18. Bates JHT, Rossi A, Milic-Emili J 1985 Analysis of the behavior of the respiratory system with constant inspiratory flow. J Appl Physiol 58:18401848

19. Mead J, Whittenberger JL 1954 Evaluation of airway interruption technique as a method for measuring pulmonary air-flow resistance. J Appl Physiol 6:408-416

20. Hughes RA, May AJ, Widdicombe J 1959 Stress relaxation in rabbit's lungs. J Physiol 146:85-97

21. Shephard RJ 1963 Mechanical characteristics of the human airway in relation to use of the interrupter valve. Clin Sci (Lond) 25:263-280

22. Sly PD, Bates JHT 1988 Computer analysis of physical factors affecting the use of the interrupter technique in infants. Pediatr Pulmonol 4:219-224

23. Wall MA 1980 Infant endotracheal tube resistance: effects of changing length, diameter and gas density. Crit Care Med 8:38-40

24. Orkin L, Siegel M, Rovenstine E 1954 Resistance to breathing by apparatus used in anesthesia. Curr Res Anesth Analg 33:217-233

25. Chang HK, Mortola JP 1981 Fluid dynamic factors in tracheal pressure measurement. J Appl Physiol 51:218-225

26. Mead J, Takishima T, Leith D 1970 Stress distribution in lungs: a model of pulmonary elasticity. J Appl Physiol 28:596-608

27. Loring SH, Elliott EA, Drazen JM 1979 Kinetic energy loss and convective acceleration in respiratory resistance measurements. Lung 156:33-42

28. Nicolai T, Lanteri CJ, Sly PD 1991 Tissue viscoelastic time constant and coupling of dissipative and elastic behaviour of the lung. Am Rev Respir Dis 143:A538(abstr)

29. Sly PD, Lanteri CJ, Nicolai T 1992 Volume-dependence of the viscoelastic time constant. Am Rev Respir Dis 145:A591(abstr) 